\title{
PROFESSIONAL RELIABIIITY OF LOCOMOTIVE DRIVER UNDER SHIFTWORK: EFFECT OF BIOLOGICAL AND SOCIAL FACTORS
}

\author{
Bobko N.A.
}

\section{ПРОФЕССИОНАЛЬНАЯ НАДЕЖНОСТЬ МАШИНИСТА ЛОКОМОТИВА В УСЛОВИЯХ СМЕННОГО ТРУДА: ВЛИЯНИЕ БИОЛОГИЧЕСКИХ И СОЦИАЛЬНЫХ ФАКТОРОВ}

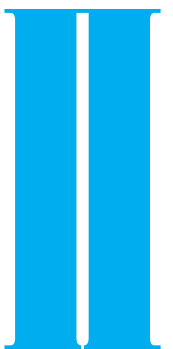

БОБКО Н.А.

ГУ "Институт медицины труда НАМН Украины,

г. Киев

УДК

$612.766 .1+57.03+57.04: 001.5$

Ключевые слова: сменный труд, надежность человека-оператора, биологические и социальные факторы. роблема безопасности движения на железнодорожном транспорте во многом связана с проблемой надежности человека-оператора, управляющего движением подвижного состава: до 70\% аварий происходит по вине членов локомотивных бригад. Научно-технический прогресс, с одной стороны, приводит к снижению аварийности, с другой - к непрекращающемуся росту требований к психофизиологической сфере человека-оператора, особенно при переходе к работе «в одно лицо», когда один машинист управляет движением локомотива. Вредные и опасные условия труда обусловливают ускоренное ухудшение состояния здоровья машинистов локомотивов, а значит и эффективности их умственной деятельности. При таких обстоятельствах хорошо отработанные методы профотбора, ежегодного медицинского переосвидетельствования, текущего контроля функционального состояния могут решать часть проблем безопасности движения за счет отстранения от работы или вывода из профессии лиц, утративших свою пригодность к надежной работе. Системы профессиональной подготовки, психологической коррекции текущего состояния машиниста, оптимизации микроклимата в коллективах помогают дольше сохранить требуемую профессиональную надежность машинистов. При этом нервно-эмоциональное напряжение и нарушения режима труда и отдыха называют в числе ведущих вредных условий труда, формирующих заболеваемость с временной утратой трудоспо-
ПРОФЕСІЙНА НАДІЙНІСТЬ МАШИНІСТІВ ЛОКОМОТИВІВ В УМОВАХ ЗМІННОЇ ПРАЦІ: ВПЛИВ БІОЛОГІЧНИХ І СОЦІАЛЬНИХ ФАКТОРІВ Бобко Н.A.

ДУ "Інститут медицини праці НАМН України", м. Київ

Мета дослідження: виявити вплив чинників біологічної і соціальної природи на професійну надійність машиніста локомотива в умовах змінної праці.

Матеріали і методи дослідження: аналітичний огляд літератури бібліотечних фондів і електронних баз даних (Medline, Pubmed, CIS, Embase) через Інтернет з використанням пошукових комп'ютерних технологій (Google, Yahoo, Рамблер) засобами веб-інтерфейсу $i$ клієнт-серверних систем управління базами даних. Результати дослідження. Існуючі системи профвідбору, профпідготовки, контролю та корекції стану недостатньо ефективні для забезпечення надійної повсякденної роботи машиністів локомотивів. Шкідливі і небезпечні умови праці посилюють розвиток втоми, яка $\epsilon$ однією з основних вихідних причин аварійності на транспорті. Закономірності їі формування тісно пов'язані з часом доби, тривалістю і напруженістю робочої зміни, циклу робочих змін, з періодом року, з віком людини, погоднокліматичними та геомагнітними умовами. Так, добовий ритм потенціює відчуття втоми у нічний час, у ранні ранкові години і мінімізує його у денний і вечірній час. Частота проїздів забороняючих сигналів збільшується після 8-10 годин безперервного водіння і сягає 7-9-кратних величин на 12-22-й годинах роботи. Ризик аварійності через провини машиністів локомотивів подвоюється після 4-6 годин водіння порівняно з першими годинами роботи, після 10 послідовних робочих днів порівняно з першими п'ятьма, $\epsilon$ максимальним від півночі до 4 години ранку, у лютому і серпні. Молоді реагують на події на дорозі швидше, але в аварії попадають частіше. Втома з віком розвивається швидше, відновлення - повільніше. Найбільш ефективним способом профілактики передчасного розвитку втоми $\epsilon$ достатній якісний сон. Однак його тривалість у вагоні на 25\% коротша, ніж удома, структура сну змінена. Дефіцит сну та стомлюваність найбільші при нічних і ранніх ранкових змінах. Погіршення погоди (опади), збільшення напруженості геомагнітного поля Землі підвищують ризик залізничних подій.

Висновок. Оптимізація умов праці, дизайну та обладнання кабін, залізничних переїздів, максимально можливе врахування біологічних і природних факторів зниження ефективності керуючої діяльності машиністів при вдосконаленні хронобіологічних основ режимів праці та відпочинку є резервом підвищення їхньої професійної надійності.

Ключові слова: змінна праця, надійність людини-оператора, біологічні та соціальні чинники.

( Бобко Н.А. СТАТТЯ, 2016. 
собности машинистов. Вместе с тем недостаточно изученными и учитываемыми при разработке графиков сменности остаются возможности человеческого организма при существующем комплексе производственных требований, в частности, при необходимости одинаково надежной работы в разное время суток, при продленных или нерегулярных рабочих сменах, при разной текущей рабочей нагрузке.

Цель нашей работы была изучить и проанализировать состояние проблемы по данным зарубежных авторов.

Непосредственными причинами аварий и крушений на железнодорожном транспорте называют проезды запрещающих сигналов [13], неудовлетворительное обустройство переездов через железнодорожное полотно [48], несогласованность действий машиниста локомотива с начальником станции [9] или действий работников путевых бригад [10], привходящее влияние стресса (связанного с работой, жизнью, окружающей средой) $[18,11]$ и др.

При этом проезды запрещающих сигналов, в свою очередь, могут быть следствием утомления, засыпания во время управления локомотивом, недостаточной внимательности, отвлечения машиниста, запоздалого восприятия сигнала, неправильного восприятия команды распорядителя маневров, позднего применения тормозов, нарушения должностных инструкций, правил технической эксплуатации, незнания техникораспорядительного акта, технических неисправностей и др. [13, 12]. Непреднамеренные ошибки или неверные действия членов локомотивных бригад, которые отмечаются наряду с ненадежным (небезопасным) поведением, могут быть следствием роста рабочей нагрузки, неэффективности средств индивидуальной защиты, несовершенства организации труда [13]. В ряде случаев проезды запрещающих сигналов связывают с предощущением невозможности справиться с конкурирующими требованиями ситуации [12].

Риск проезда запрещающих сигналов повышается при сочетанном влиянии несколь-

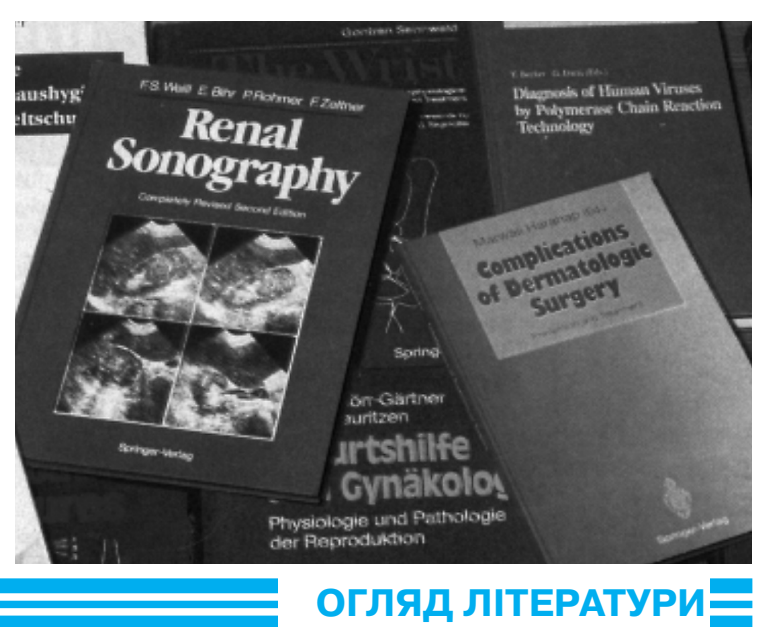

ких неблагоприятных факторов, например таких, как дефицит времени, отвлечение внимания от здания вокзала, появление непредвиденных новых событий. По сути, большинство неблагоприятных психосоциальных факторов провоцирует смещение внимания машиниста и вносит вклад в формирование роста его тревожности [12], которая сама по себе является известным фактором, снижающим надежность человека-оператора.

Степень травмирования участников дорожного движения во время аварий и крушений на железнодорожном транспорте при пересечении железнодорожных переездов зависит от наличия активных предупреждающих сигналов (звука, мигающего красного света), длинного сооружения возле переезда, типа железной дороги, а также от возраста человека, управляющего транспортным средством, времени суток, погоды (наличия осадков - снега, дождя), роли транспортных средств в аварии и действий автомобилиста, предшествующих аварии [14].

Одной из основных исходных причин нарушения безопасности движения на железнодорожном транспорте является утомление [15-20], усугубляющееся в силу высокого нервноэмоционального напряжения, особенностей сменного графика работы, продленных рабочих часов, некачественного отдыха (особенно в вагонах и на станциях), неблагоприятных физических факторов условий труда (шума, вибрации, электромагнитных полей, микроклиматических условий, состава воздуха рабочей зоны, резкой смены климатических и погодных факторов), несовершенного дизайна кабины машиниста локомотива. В классической литературе утом- ление определяют как временное снижение работоспособности, вызванное проведенной работой или как комплекс функциональных сдвигов, возникающих при интенсивной или продолжительной работе и обусловливающих временное обратимое снижение работоспособности физиологических систем или целостного организма. Субъективно утомление ощущается как усталость.

Объективное и субъективное утомление у машинистов грузовых локомотивов увеличивалось к концу 8-часовых смен, однако 8 часов отдыха было достаточно для восстановления исходных уровней функционирования организма во избежание накопления утомления в течение 4-суточного рейса [15]. При 12-часовых сменах в условиях вахтовой работы (7 дневных смен, сутки отдыха, 7 ночных смен, 7 или 14 суток отдыха) в большинстве случаев усталость в конце смены ощущалась сильнее, чем в начале, но если смена начиналась в 22:00-4:00 (и заканчивалась в 10:00-16:00), то усталость оценивалась машинистами одинаково и в начале, и в конце смен. В начале смен утомление ощущалось больше всего, если смены начинались в 22:00-4:00, меньше всего - при начале смен в 10:00-16:00. В конце смен утомление ощущалось больше всего, если смены оканчивались в 22:00-4:00, меньше всего - в 16:00-22:00 [18]. Таким образом, циркадный ритм оказывает существенное влияние на чувство усталости, потенцируя его в ночное время (22:004:00) и минимизируя в дневное и вечернее (10:00-16:00, 16:0022:00).

Усталость в начале смен в наибольшей мере коррелировала с оценкой восстановления после предыдущей смены, в конце смены - со временем 
окончания смены, длительностью смены и степенью восстановления. Степень восстановления в начале последовательности смен зависела от продолжительности отдыха и временных рамок первой смены, в течение блока смен от особенностей и временных рамок самих смен [23].

Наиболее важным фактором, определяющим усталость в начале смен, было время суток с максимальными значениями в ранние утренние часы, в конце смен - время суток, продолжительность смены, непрерывного вождения, нахождения в кабине и вид смены. Наиболее утомительны ночные смены, тесно примыкают к ним смены с ранним началом. Утомительность от продолжительности вождения и нахождения в кабине варьировала в зависимости от вида смен и была наибольшей при раннем начале смен. Непреднамеренное закрытие глаз отмечалось в 36\% смен с ранним началом, в 32\% ночных смен, дремота - в 9\% и $43 \%$ соответственно [19]. Субъективная оценка количества допускаемых при вождении ошибок показала, что 80\% машинистов локомотивов считают, что больше всего ошибок они допускают в сменах с ранним началом, менее $10 \%$ - в ночные смены [24].

Относительная частота аварийности по вине машинистов локомотивов возрастала в течение первых полутора часов непрерывной работы, оставалась на достигнутом уровне до 4.5 ч работы без перерыва и удваивалась после 6 ч работы (без учета непредусмотренных перерывов) [25] (на дорогах Англии). Риск аварийности удваивался после 4 ч вождения по сравнению с первым часом, для грузовых поездов отмечался дополнительный рост риска на первом часу в связи с орга- низационными мероприятиями [17] (на дорогах Тайваня). Относительно более раннее удвоение риска аварийности (в Тайване) может быть связано с более ранним развитием утомления у машинистов как следствие худших условий труда и быта в экономически менее развитой стране.

Причем относительный риск аварийности сохранялся на одинаковом уровне в течение первых 5 последовательных дней работы, резко возрастал после 6 дней и удваивался после 10 рабочих дней [16].

Утомление снижает безопасность машинистов в такой же степени, как опьянение средней степени, вызывая непреднамеренное отключение внимания от управления локомотивом [26]. Для борьбы с развивающимся утомлением машинисты используют пребывание на свежем воздухе, еду и питье, в том числе напитки с кофеином [24]. Потребление кофе у машинистов локомотивов в рабочие дни больше, чем в выходные, и это коррелирует с увеличением периода засыпания, укорочением сна и ухудшением настроения [27]. Кроме того, кофеин повышает работоспособность, скорость умственной деятельности, но не ее качество, а через 1-2 ч его эффект нивелируется, и потому требуется следующая и следующая порция. Поэтому за кажущимся кратковременным решением проблемы утомления с помощью кофеина стоит усугубление проблем здоровья, качества жизни и безопасности вождения, что актуализирует необходимость разъяснительной работы среди членов локомотивных бригад.

Основным природным способом предупреждения развития преждевременного утомления является достаточный качественный сон. Однако в условиях сменного труда жалобы на проблемы сна возникают в первую очередь и являются наиболее распространенными.

Так, нехватка сна наибольшая при ночных и ранних утренних сменах [28]. Продолжительность сна накануне смен с ранним началом зависит от времени начала и последовательного номера смены с ранним началом, сокращаясь от 7.08 ч перед поздним утренним началом до 4.77 ч перед сменой с началом в
4:00-4:30. Продолжительность сна возрастала от первой ко второй последовательной смене с ранним утренним началом на 0.36 ч, от 2-й до 4-й - на 0.22 ч. Однако она снижалась на 10 минут при сдвиге начала смен на каждый час в сторону более раннего [19].

Непреодолимая сонливость на работе ночью была в 6-14 раз выше, в утренние смены - в 2 раза выше, чем в дневные. Варьировала у 36-62\% машинистов в зависимости от текущих условий смены. Дремота отмечалась у 9-31\% машинистов. Основной период сна перед ночными сменами был сокращен на 2 ч, если утренняя смена предшествовала ночной, а перерыв составил минимум 3-6 ч (эталон). Наиболее сокращен сон между двумя последовательными ночными сменами (до 2.9-3.5 ч). Риск послеобеденной дремоты увеличивался, если утренняя или дневная смены непосредственно предшествовала ночной (4.4-4.8 по сравнению с эталоном).

Основной сон перед утренней сменой сокращался на 0.5 ч, если вечерняя смена предшествовала утренней по сравнению со сном после выходного дня. Риск сонливости и дремоты не зависел от вида предшествующей смены, но зависел от ее длительности, времени начала утренней смены (непреодолимая сонливость) и длительности предшествующего сна. Индивидуальная потребность во сне увеличивала длительность сна и риск непреодолимой сонливости. Увеличение возраста не влияло на сон перед утренней или ночной сменами, на дремоту на работе, но было связано со снижением риска непреодолимой сонливости [29].

Чем дольше перерыв между периодами непрерывного вождения, тем больше длительность сна (в одно и то же время суток), при этом короткие перерывы не давали возможности достаточного отдыха. За 12-часовые перерывы $\mathrm{coH}$ составлял 3.1-7.9 ч. В ночные перерывы длительность сна увеличивалась [30]. При 8часовом ожидании в сменном вагоне машинисты спали в среднем 3.2 ч. В частности, при этом было зарегистрировано 30 мин. (15\%) медленноволно- 
PROFESSIONAL RELIABILITY OF LOCOMOTIVE DRIVER UNDER SHIFTWORK: EFFECT

OF BIOLOGICAL AND SOCIAL FACTORS

\section{Bobko N.A.}

SI "Institute for Occupational Health of NAMS of Ukraine", Kyiv

Objective. We revealed the effects of biological and social nature factors on the professional reliability of locomotive driver under shiftwork. Materials and methods. We performed the analytical literature review of the library and electronic databases (Medline, Pubmed, CIS, Embase) via Internet using search computer technology (Google, Yahoo, Rambler) by means of web-based and client-server database management systems. Results. The existing systems of professional selection, training, body state control and correction are not effective enough to ensure the reliable daily operation of locomotive drivers. Harmful and dangerous working conditions exacerbate the development of fatigue, which is one of the underlying causes of transport accidents. Regularities of its de-velopment are closely related to the time of day, duration and intensity of the work shift, the shift series, time of the year, with human age, weather, climate and geomagnetic condi-tions. Thus, the circadian rhythm potentiates feeling tired at night, in the early morning hours and minimizes it at the afternoon and evening. The frequency of a signal passed at danger increases after 8-10 hours of continuous operation and increases up to 7-9 times at the 12-22-nd hours of working. The accident risk due to the fault of locomotive drivers doubled after 4-6 hours of driving compared to the first hours of operation, after 10 con-secutive working days compared to the first five ones, reached maximum scores from mid-night to 4 a.m., in February and August. Young drivers react to the road events quickly, but the accident commit more frequently. Ageing speeds the fatigue development and de-lays the recovery. The most effective way to prevent the early fatigue development is the sufficient quality sleep. However, its duration in a car is 25\% shorter than at home, the sleep structure is changed. Both the sleep deficit and tiredness are the greatest at night and early morning shifts. Bad weather (precipitation), an increase in intensity of the Earth geomagnetic field increases the risk of railway incidents.

Conclusion. Optimization of working conditions, design and equipment of cabins, railway crossings, the maximum possible taking into consideration of the biological and environ-mental factors reducing the effectiveness of driving activities while improving chronobi-ological bases of working and rest regimes are a reserve for increase of the locomotive drivers professional reliability.

\section{Keywords: shift work, human-operator} reliability, biological and social factors. вого сна и 45 мин. (21\%) быстрого (БДГ), тогда как дома при общей длительности сна 6.3 ч - 43 мин. (11\%) и 102 мин. (27\%). Скрытый сон (к стадии 1) составил 13.6 мин. в первом случае и 31.1 мин. - во втором, отражая большую сонливость в первом случае. Эффективность сна в обоих случаях была меньше 75\%. Субъективная оценка сна не различалась [31]. Таким образом, в пересчете на 24-часовый суточный цикл общая продолжительность сна в вагоне была 4.8 ч, что меньше, чем дома (6.3 ч) при тенденции к большей сонливости, относительно более длительному восстановлению преимущественно физических ресурсов организма (15\% по сравнению с 11\%) и укороченному восстановлению интеллектуальных возможностей (21\% по сравнению с 27\%).

После ночных смен сонливость выше, чем после дневных, однако сон (дневной) сокращен на 3.3 ч (за счет стадии БДГ и 2-й стадии), диурез и экскреция НА в течение дневного сна выше, чем в течение ночного. С возрастом (в 50-60 лет) негативное влияние ночных работ на сон увеличивается: перечисленные признаки усугубляются, удлиняется 1 стадия сна, учащаются пробуждения [32].
Более короткие (чем 24-часовые) циклы чередования работы и отдыха, как и срочные вызовы на работу, сопровождаются более коротким и менее качественным сном [33].

Положительный эффект дремоты перед ночными сменами в условиях нерегулярного чередования смен известен [28], однако известны и ее побочные эффекты - некоторое снижение скорости засыпания и длительности сна, чувства восстановления после сна [34].

Поскольку сон - состояние измененного метаболизма, то его сокращения, нарушения и перемещения во времени имеют неблагоприятные отдаленные последствия для эндокринной, иммунной систем и обмена веществ в целом, могут приводить к заболеваниям ССС, диабету 2 типа, хроническим воспалительным процессам [35]. C увеличением стажа работы машиниста локомотива в крови увеличивается концентрация глюкозы, триглицеридов, общих липопротеидов, липопротеидов низкой плотности, что коррелирует с увеличением объема талии, бедер, массы тела и риска остановки дыхания во сне [36]. В частности, среди машинистов локомотивов в Англии выявлено 56\% лиц с проблемами сна, 16\% из которых имели синдром остановки дыхания во сне [24]. В Бразилии среди машинистов с проблемами сна 59\% имели синдром апноэ [37]. Нарушения сна повышают риск сонливости и аварийности. В Украине до половины случаев потери профпригодности членов локомотивных бригад происходит по причине развития гипертонической болезни. у каждого пятого повышен риск внезапной смерти, у каждого восьмогодесятого - бессимптомное протекание клинических форм патологии CСС, которые могут привести к острым осложнениям и летальным последствиям на транспорте.

Влияние биологических и социальных ритмов на эффективность управляющей деятельности машиниста. Эффективность деятельности является функцией человеческого организма, а потому может изменяться вследствие суточных и годовых (сезонных) биоритмов в связи с 7-дневным циклом активности общества.

Так, качество съема информации со счетчиков и частота, с которой машинисты локомотивов отвечали на предупредительные сигналы, имели вид двойной синусоиды с минимумами в 3 ч и 13-14 ч, максимумами - в 16-18 ч и 8-11 ч. 
возраста. В экспериментальных условиях моделирования вождения с одинаковым внезапным торможением из-за удара в заднюю часть состава «аварии» случались у 35\% молодых и неопытных водителей, в то время как у опытных машинистов не случались вовсе. Однако во время торможения короткая длительность продолжающегося движения поезда (не превышающая 2-3 секунд) у молодых регистрировалась вдвое чаще, чем у опытных водителей (у 50\% и 25\% соответственно) [39]. Более быстрая реакция молодых людей обусловлена большей скоростью проведения возбуждения по их нервным волокнам [40], что проявляется также в лучших скоростных показателях выполнения разных психофизиологических тестов [41]. Однако эта же быстрая реакция может оказаться недостаточно продуманной и привести к аварии. Так, среди молодых водителей с короткой длительностью движения состава после торможения 70\% совершили «аварию». При этом группы молодых, попавших в «аварию», избежавших ее, и опытных водителей различались существенно по положению дросселя и силе давления на тормозную педаль [39].

Возрастные ограничения работы на водительских должностях обусловлены прежде всего возрастным снижением скорости реакции человека $[40,41]$, а также более быстрым развитием утомления и медленным восстановлением [42].

Влияние колебаний напряженности геомагнитного поля Земли. Известно, что машинисты и члены локомотивных бригад умирают от внезапной остановки сердца на рабочем месте в магнитоактивные дни в 2.38 раза чаще, чем в магнитоспокойные, вне работы - в 1.52 раза чаще [43]. Повышенную чувствительность членов локомотивных бригад к колебаниям ГМП связывают с профессиональным контактом этих лиц с электромагнитными полями [44], поскольку влияния сходного происхождения взаимно усиливаются в их воздействии на организм. Кроме того, колебания ГМА больше влияют на людей ослабленных, находящихся в условиях нервноэмо- ционального стресса, повышенного напряжения [45], что характерно для труда машинистов локомотивов.

Предлагаются мероприятия для профилактики аварийности и снижения степени травмирования участников железнодорожных происшествий:

- улучшение гигиенических условий труда за счет внедрения современных инженерных решений, физиолого-гигиенических и психологических разработок, включая снижение рабочей нагрузки (напряженности труда);

- совершенствование дизайна и оборудования кабин для повышения эффективности управления движущимся поездом (современные системы управления базируются на информации с дисплея, традиционные - на необработанной информации из реального мира - сложной многокомпонентной и чрезвычайно динамичной системы [45]), для улучшения защиты машиниста во время столкновения [46], для учета особенностей левшей (поскольку левши с ведущей левой рукой или ногой, но не глазом или ухом, чаще совершают аварии) [47];

- совершенствование дизайна и обустройства железнодорожных переездов с использованием, кроме пассивного запрещающего сигнала, также активных сигналов - звука при поднятии шлагбаума, мигающего красного света, сооружение длинного барьера (ворот, здания, любого сооружения: только добавление ворот снижало количество автомобилей, пересекающих железную дорогу прямо перед поездом, почти вдвое - с 67\% до 38\%) [46];

- использование программных сценариев для моделирования вождения в обучающих, тренирующих и исследовательских целях [48], для тренировки профессионально важных высших психических функций [49], для психологического тренинга самостоятельного управления эмоциями [11];

- совершенствование графиков чередования смен с учетом суточных биоритмов и временных закономерностей формирования эффективности профессиональной деятельности машиниста, использование образовательных программ для работающих в сменпрофессий на транспорте известен повышенный риск аварийности у лиц младшего 
ном режиме при нерегулярных графиках на транспорте в целях улучшения соблюдения ими гигиены сна, питания, отдыха, поддержания физической формы для сохранения здоровья, продления профессионального долголетия и повышения безопасности труда [31, 50];

- совершенствование системы профессионального отбора, в частности, предлагается ограничение возраста машинистов электровозов (например, в Китае - 50 годами [16], в Украине пенсионный возраст машиниста - 55 лет).

Наряду с безусловной целесообразностью оптимизации гигиенических условий труда, совершенствования эргономичности кабин, надлежащего обустройства железнодорожных переездов, с хорошо зарекомендовавшими себя методами профотбора, переосвидетельствования, профессиональной подготовки, психологически обоснованного формирования коллективов, контроля текущего функционального состояния и его психологической коррекции, новыми эффективными методами обеспечения безопасности движения могут служить способы искусственного поддержания высокого уровня бодрствования человека за рулем. В частности, расположение ярких рекламных щитов по бокам автотрасс или телемеханическая система контроля бодрствования машиниста, основанная на работе с КГР человекаоператора (за 15 лет ее эксплуатации в периоды использования системы не зафиксировано ни одного случая проезда запрещающего сигнала). Однако такие методы предполагают искусственное поддержание постоянно повышенной активации симпатической нервной системы, что противоречит волнообразной природе адаптации человека (и потому может вызывать ускоренное развитие утомления), а также повышает риск формирования гипертонии, коронарной патологии при снижении сохранности функции сердца [51]. Использование таких методов требует физиологогигиенических исследований для разработки адекватных режимов их применения. Одним из перспек- тивных, щадящих человеческие ресурсы подходов к профилактике аварийности представляется разработка хронобиологически обоснованных графиков сменности, режимов труда, питания и отдыха на основе изучения суточных закономерностей формирования утомления при разных графиках чередования смен с разной рабочей нагрузкой.

\section{REFERENCE}

1. Lawton R., Ward N.J. Accid. Anal. Prev. 2005; 37 (2) :

\section{5-244.}

2. Stanton N.A., Walker G.H. Accid. Anal. Prev. 2011; 43 (3) : 1117-1127.

3. Van der Flier $\mathrm{H}$. and Schoonman W. Appl. Ergon. 1988; 19 (2) : 135-141.

4. Lenne M.G., Rudin-

Brown C.M., Navarro J., Edquist J., Trotter M., Tomasevic N. Appl. Ergon. 2011; 42 (4) : 548-554.

5. Tey L.S., Ferreira L., Wallace A. Accid. Anal. Prev. 2011; 43 (6) : 2134-2141.

6. Meeker F., Fox D., Weber C. Accid. Anal. Prev. 1997; 29 (1) : 11-16.

7. Lopes M.G., de Gouveia Vilela R.A., de Almeida I.M., Mioto O.L., Takahashi M.A., Perin F.O. Work. 2012; 41 (Suppl. 1) . 3148-3154

8. Salmon P.M., Read G.J., Stanton N.A., Lenne M.G. Accid Anal Prev. 2013; 50 : 1278-1288

9. Frey F.G. Klin. Monbl. Augenheilkd. 1975; 167 (1) : 125-127.

10. Santos-Reyes J.,

Beard A.N. Accid. Anal. Prev. 2009; 41 (6) : 1133-1144.

11. Rowden P., Matthews G., Watson B., Biggs H. Accid. Anal. Prev. 2011; 43 (4) : 1332-1340.

12. Naweed A. Accid. Anal. Prev. 2013; 60 : 193-204.

13. Misawa R., Inadomi K., Yamaguchi $H$. Shinrigaku Kenkyu. 2006; 77 (2) : 132-140.

14. Eluru N., Bagheri M., Miranda-Moreno L.F., Fu L. Accid. Anal. Prev. 2012; 47 : 119-127.

15. Jay S.M., Dawson D., Ferguson S.A., Lamond N. Appl. Ergon. 2008; 39 (5) : 623-629.

16. Zhou D.S. Zhonghua Yu Fang Yi Xue Za Zhi. 1991; 25 (1) : 26-29.

17.Chang H.L., Ju L.S. Accid. Anal. Prev. 2008; 40 (6) :

1844-1849.

18.Paech G.M., Ferguson S.A., Sargent C., Roach G.G. Shiftwork International Newslet-ter. 2011; 25 (3) : 38
19. Turner C., Spencer M.B., Stone B.M. Shiftwork International Newsletter. 2005; 22 (2) : 150.

20. Fournier P.S., Montreuil S. Brun J.P. Work. 2007; 29 (3) : 213-224.

21. Rozenblat V.V. Utomlenie [Fatigue]. In : Zolina Z. M., Izmerov N.F. (eds.) Rukovodstvo po fiziologii truda [Guides on Labour Physiology]. Moscow : Meditsina ; 1983 : 227-250 (in Russian).

22. Navakatikian A.O., Kryzhanovskaia V.V., Kalnish V.V. Fiziologiia i gigiena umstvennogo truda [Physiology and $\mathrm{Hy}-$ giene of Mental Labour ]. Kiev: Zdorovia ; 1987 : 152 p. (in Russian).

23. Robertson K., Spencer M., Hesketh S. Shiftwork International Newsletter. 2011; 25 (3) : 51.

24. McGuffog A.L. Shiftwork International Newsletter. 2005; $22(2)$ : 107.

25. Spencer M.B. Shiftwork International Newsletter. 2005; 22 (2): 144.

26. Roach G.D., Dorrian J., Fletcher A., Dawson D. J. Hum. Ergol. (Tokyo). 2001; 30 (1-2) : 125-130.

27. Dekker D.K., Paley M.J., Popkin S.M., Tepas D.I. Ergonomics. 1993; 36 (1-3) : 233-238.

28. Tirilly G., Cabon P., Beslot $P$. Shiftwork International Newsletter. 2011; 25 (3) : 198.

29. Harma M., Sallinen $M$. Shiftwork International Newsletter. 2005; 22 (2): 68

30. Roach G.D., Reid K.J.,

Dawson D. Occup. Environ. Med. 2003; 60 (12): 917-923.

31. Jay S.M., Dawson D. Lamond N. Chronobiology Int. 2006; 23 (6): 1241-1252.

32. Torsvall L., Akerstedt T., Gillberg M. Scand. J. Work Environ. Health. 1981; 7 (3) :

196-203.

33. Pilcher J.J., Cople M.K. Ergonomics. 2000; 43 (5) : 573-588. 
34. Pilcher J.J., Popkin S.M., Adkins K, Roether L. Ind. Health. 2005; 43 (1) : 123-128.

35. Akerstedt T., Nilsson P.M. J. Int. Med. 2003; 254 (1) : 6-12. 36. Moreno C.R., Carvalho F.A., Lorenzi C., Matuzaki L.S., Prezotti S., Bighetti P. et al. Chronobiol. Int. 2004; 21 (6) : 871-879.

37. Teixeira C.W., Narciso F.V., Silva L.O., Koyama R.G., Esteves A.M., Bittencourt L.R.A. et al. Shiftwork International Newsletter. 2011; 25 (3) : 203.

38. Folkard S. Effects on Performance Efficiency. In : Colquhoun W.P., Costa G., Folkard S., Knauth P., (eds). Shiftwork. Problems and Solutions. Frankfurt am Main; Berlin; Bern; New York; Paris; Wien : Lang ; 1996 : 113-139.

39. McDonald C.C., Seacrist T.S., Lee Y.C., Loeb H., Kandadai V., Winston F.K. Headway Time and Crashes among Novice Teens and Experienced Adult Drivers in a Simulated Lead Truck Braking Scenario. In: Proc. Int. Driv. Symp. Hum. Factors Driv. Assess. Train Veh. Des. 2013 : 439-445.

40. Ferrario V.F., Tredici G. Crepsi V. Chronobiologia. 1980; 7 (2) : 205-209.

41. Reid K., Dawson D. Occup. Environ. Med. 2001; 58 (1) :

58-62.

42. Folkard S. Chronobiol. Int. 2008; 25 (2) : 183-198.

43. Kazimierska E. Pol Merkur Lekarski. 2001; 10 (55) : 9-11.

44. Zakharov I.G., Tyrnov O.F. Adv. Space Res. 2001; 28 (4) : 685-890.

45. Naweed A. Appl. Ergon 2014; 45 (3) : 462-470.

46. Hault-Dubrulle A., Morvan H., Robache F., Drazetic P., Landsheere C., LuC O. Comput. Methods Biomech. Biomed. Engin. 2013: 16 (Suppl. 1) 184-186.

47. Bhushan B., Khan S.M. Laterality. 2006; 11 (5) : 395-404

48. Naweed A., Hockey G.R. Clarke S.D. Appl. Ergon. 2013; 44 (3) : 445-454

49. Goode N., Salmon P.M., Lenne M.G. Appl. Ergon. 2013; 44 (3) : 435-444.

50. Howarth H., Morrow S., Coplen M., Popkin S., Snow J., Ranney J. et al. Shiftwork International Newsletter. 2011; 25 (3) : 100.

51. Knutsson A. Occup. Med 2003; 53 (2) : 103-108.

Надійшла до редакції 10.02.2015
PROFESSOR VLAS ZAHAROVYCH MARTYNYUK IS THE FOUNDER OF LVIV SCIENTIFIC AND HYGIENIC SCHOOL [to the 120-th anniversary of his birthday]

Fedorenko V.I, Kitsula L.M., Panyshko U.M., Kozak L.P.

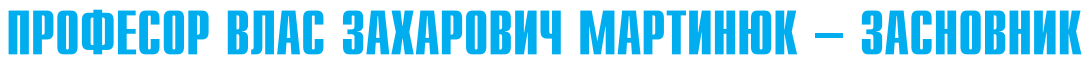
ЛЬВІвСЬКОї НАУКОВОї ГІГІЕНИЧНӦ̈ ШКОЛИ [gо 120-річчя віg gня народження]

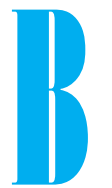

лас Захарович Мартинюк народився 22 лютого 1896 року у селі Великі Взводи Брестської області, у Білорусі, у родині Мартинюків Захарія Захаровича і Стефаниди Иосипівни, був

ФЕДОРЕНКО В.І., КІЦУЛА Л.М.,

ПАНИШКО Ю.М., КОЗАК Л.П. старшим з п'яти дітей у сім'ї. Батько працював робітником на залізниці. Жили бідно. Після навчання у церковній школі допомагав батькові у роботі, надалі вирішив поєднати своє життя з медициною і 1910 року поїхав на навчання до Кронштадтської фельдшерської школи. Отримавши диплом військового фельдшера у 1914 р. Влас Захарович був скерований на ескадровий міноносець досліджень, наукові праці

ПРОФЕССОР ВЛАС ЗАХАРОВИЧ МАРТЫНЮК - ОСНОВАТЕЛЬ ЛЬВОВСКОЙ НАУЧНОЙ ГИГИЕНИЧЕСКОЙ ШКОЛЫ

(к 120-летию со дня рождения)

Федоренко В.И., Кицула Л.М., Панышко Ю.М., Козак Л.П. Львовский национальный медицинский университет им. Данила Галицкого

Цель работы: изложить жизненный и творческий путь профессора Мартынюка В.3.

Материалы исследования: архивные материалы ЛНМУ

им. Данила Галицкого, публикации о научной и педагогической деятельности проф. Мартынюка В.З., научные работы,

авторефераты диссертаций.

Результаты. Освещен жизненный путь, научная и педагогическая деятельность профессора Мартынюка В.3. - ученого-гигиениста, заведующего кафедрой общей гигиены Львовского медицинского института (1946-1970), Заслуженного деятеля науки Украины,

ученика академика Марзеева А.Н., основателя Львовской научной гигиенической школы.

Ключевые слова: профессор Мартынюк. В.З., научная и педагогическая деятельность, направления научных исследований, научные работы.

PROFESSOR VLAS ZAHAROVYCH MARTYNYUK IS THE FOUNDER OF LVIV SCIENTIFIC AND HYGIENIC SCHOOL

(to the 120-th anniversary of his birth)

Fedorenko V.I, Kitsula L.M., Panyshko U.M., Kozak L.P.

Danylo Halytsky Lviv National Medical University

Objective: to present the life and work of professor Martynyuk V.Z.

The research materials: archival materials of Danylo Halytsky Lviv National Medical University. Publications of scientific and pedagogical activities of professor Martynyuk V.Z., scientific works, abstracts of theses.

Results. The way of life, the scientific and teaching activities of professor Vlas Zaharovych Martynyuk - head of the department of general hygiene of Lviv Medical Institute (1946-1970), the honored worker of science of Ukraine, the pupil of academician A.N. Marzeev, the founder of Lviv scientific and hygienic school have been described. Keywords: professor Vlas Zaharovych Martynyuk, scientific and educational activities, the scientific direction of researches, scientific works.

() Федоренко В.І., Кіцула Л.М., Панишко Ю.М., Козак Л.П. СТАТTЯ, 2016. 